\title{
Embryonic Atrium
}

National Cancer Institute

\section{Source}

National Cancer Institute. Embryonic Atrium. NCI Thesaurus. Code C34146.

A segment of the primitive heart tube in the human embryo that partially encircles the bulbus cordis, and which persists in the adult heart as the right auricular appendage. 